\title{
Wnt5a Stimulates the Bone Formation in Tension Side during Orthodontic Tooth Movement
}

\author{
Nana Isogai, Masaru Yamaguchi, Jun Kikuta, Mami Shimizu, Tomokazu Yoshino, Takuji Hikida, \\ Momoko Takahashi, Takemi Goseki, and Kazutaka Kasai \\ Department of Orthodontics, Nihon University School of Dentistry at Matsudo, Matsudo, Chiba 271-8587, Japan
}

\section{Article History}

Received 18 February 2015

Accepted 11 May 2015
Keywords :

wnt5a, tooth movement,

bone formation, periodontal ligament

\begin{abstract}
In this study, we first investigated the expression of wnt5a in tension sites during experimental tooth movement in rats in vivo. We then assessed the effects of wnt5a on the expression of bone marker from human periodontal ligament (hPDL) cells.

Twelve male 6-week old Wistar rats were subjected to an orthodontic force of $10 \mathrm{~g}$ in order to induce the mesial tipping movement of the upper first molars for 7 days. The expression levels of wnt5a proteins in the alveolar bone were determined using an immunohistochemical analysis. Furthermore, the effects of wnt5a on the gene expressions of alkaline phosphatase (ALP) and type I collagen (COL1) were investigated using hPDL cells in vitro.

Under the conditions of experimental tooth movement in vivo, the immunoreactivity for wnt5a was detected in the tension side on day 7 in the PDL tissue of rats subjected to the orthodontic force $(10 \mathrm{~g})$. In the in vitro study, wnt5a treatment increased the gene expression of ALP and COL1 from the hPDL cells in a time-dependent manner.

These results suggest that the wnt5a stimulates the alveolar bone formation in the tension side during orthodontic tooth movement.
\end{abstract}

\section{Introduction}

Bone modeling is the uncoupled process of activationresorption (catabolic) or activation-formation (anabolic) on the bone surfaces, which results in changes of the shape, size, or position of the bone(1). Bone remodeling or turnover, on the other hand, is a tightly coupled local process, which starts with bone resorption, followed by the reversal and bone formation phases, resulting in the replacement of old bone with new bone $(2,3)$. Orthodontic tooth movement is a multistep biological process characterized by the sequential reactions of periodontal tissue against biomechanical forces (4). The recruitment of osteoclast- and osteoblast-progenitor cells, and the balanced activation of these cells around and within the periodontal ligament (PDL) are essential for alveolar bone remodeling $(5,6)$.

Wnt proteins are soluble glycoproteins that mediate

Correspondence to :

Masaru Yamaguchi

E-mail : yamaguchi.masaru@nihon-u.ac.jp homeostatic and developmental activity (7). The canonical wnts bind to receptor complexes composed of Lrp5/6 and Frizzled proteins and ultimately induce nuclear translocation of $\beta$-catenin. Noncanonical wnts bind to a variety of receptors, including receptor tyrosine kinases, and mediate many different activities, some of which oppose canonical wnt signaling. Wnt-mediated signaling promotes postnatal bone accrual (8) and is essential for skeletal outgrowth(9). Wnt proteins are in a large family of growth factors that are important for multiple cellular functions (10). Several wnt proteins, such as wnt1, 3a, 4, 5, 10b, and 13, are important for osteoblast formation through the activation of two main signaling pathways(11-13). Recently, Lim et al.(14, 15) reported that wnt signaling regulates the homeostasis of the periodontal ligament. Furthermore, wnt signaling enhanced bone formation and inhibited bone resorption. Rawadi et al. (16) reported that BMPs induced ALP expression in preosteoblasts through wnt-mediated activity. Hoe et al. (17) reported that wnt/ $\beta$-catenin signaling enhances ALP 
(A)

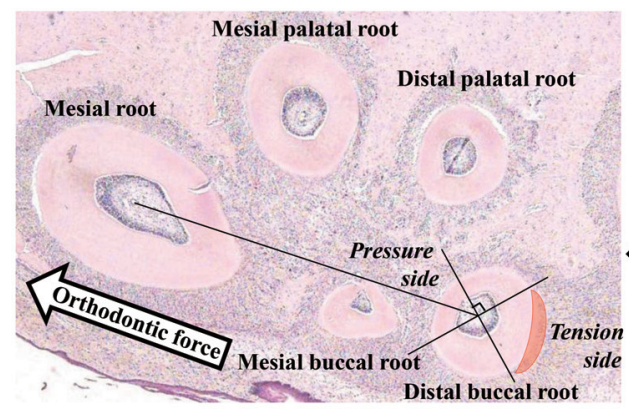

(B)

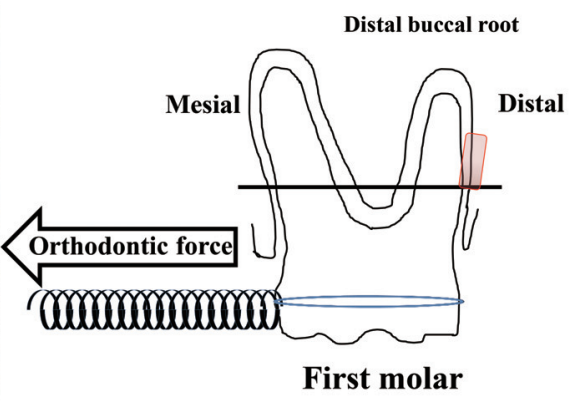

Fig.1 Experimental tooth movement. A schematic illustration showing the area of investigation (shaded box) in the distal alveolar bone aspect of the distal root of the first molar. The periodontal tissues in the tension area were a quarter of the distal area facing the distal buccal root, as determined when linked with the center of the distal buccal root and the mesial root of the first molar. The large arrow indicates the direction of the force (A). The observation of the positive cells was performed at a $300 \mu \mathrm{m}$ section (shaded box) of the alveolar bone from the bifurcation surface on the distal side, which is the tension side during tooth movement (B).

activity and matrix mineralization from hPDL cells. Therefore, it is possible that wnt signaling plays partly an important role in bone formation in the tension side during orthodontic tooth movement (OTM).

However, the role of wnt signaling during OTM is not yet fully understood. Wnt5a, a member of the noncanonical wnt proteins, is known to play important roles in the development of various organs and in postnatal cell functions. Therefore, this study focused on the relationship between OTM and wnt5a. In an in vivo experiment, we investigated the expressions of wnt5a in the tension side during experimental tooth movement in rats. We also investigated the effects of wnt5a on the mRNA expressions of alkalinephosphatase (ALP) and type I collagen (COL1) using human PDL (hPDL) cells in vitro.

\section{Materials and Methods}

In vivo studies

Animals

The animal experimental protocol used in this study was approved by the Ethics Committee for Animal Experiments at the Nihon University School of Dentistry at Matsudo (approval No. AP12MD020). A total of 12 male 6-week old Wistar rats (body weight $180 \pm 10$ g; Sankyo Labo Service, Tokyo, Japan) were used for the experiments.

Rats were randomly assigned into two groups: the control group, where rats received no application of force, and the tension force $(\mathrm{TF}) 10 \mathrm{~g}$ group, where rats were subjected to $\mathrm{TF}($ control $=6, \mathrm{TF}=6)$.

\section{Application of the orthodontic devices}

Kohno et al.(18) reported that the optimum force for the movement of the rats' upper molars may be $10 \mathrm{~g}$. Therefore, the experimental tooth movement was induced using the method of Asano et al. (19), with a closed-coil spring (wire size: 0.005-inch, diameter: 1/12 inch; Accurate, Inc., Tokyo, Japan) ligated to the maxillary right first molar with a 0.008inch stainless steel ligature wire (Tomy International, Inc., Tokyo, Japan). The other side of the coil spring was also ligated, with holes in the maxillary incisors that were drilled laterally just above the gingival papilla using a 1/4 round bur, applying the same ligature wire. The upper first molar was moved mesially by the closed-coil spring with a force of $10 \mathrm{~g}$. The period of the experiment was 7 days (Fig. 1).

\section{Tissue preparation}

The animals were deeply anesthetized using thiamylal sodium and transcardially perfused with $4 \%$ paraformaldehyde in $0.1 \mathrm{M}$ phosphate buffer, after which the maxilla was immediately dissected and immersed in the same fixative for $18 \mathrm{~h}$ at $4^{\circ} \mathrm{C}$. The specimens were decalcified in $10 \%$ disodium ethylenediaminetetraacetic acid (EDTA, pH 7.4) solution for four weeks, and the decalcified specimens were subsequently dehydrated using a graded ethanol series and embedded in paraffin. Each sample was sliced continuously into $4-\mu \mathrm{m}$ sections in the horizontal direction and prepared for hematoxylin and eosin (HE) and immunohistochemical staining. The animals in which the tooth did not move were assigned to the control group. 


\section{Immunohistochemistry}

The tissue sections were deparaffinized, and the endogenous peroxidase activity was quenched via incubation in 3\% $\mathrm{H}_{2} \mathrm{O}_{2}$ in methanol for $30 \mathrm{~min}$ at room temperature.

After washing in Tris-buffered saline, the sections were incubated with polyclonal anti-goat wnt5a (R\&D Systems Co., MN, USA) for $18 \mathrm{hrs}$ at $4^{\circ} \mathrm{C}$. Wnt5a was stained using the Histofine Simple Stain MAX-Po (G) kit (Nichirei, Co., Tokyo, Japan). Negative reactivity was observed in the control samples.

\section{In vitro studies}

hPDL cell culture

hPDL cells were prepared according to a modification of the method reported by Somerman et al. (20). Briefly, hPDL tissues were collected from the roots of premolars extracted from six healthy young volunteers [male $(n=3)$, female $(n=$ 3); age: 14-16 years] during the course of orthodontic treatment. The study was performed after obtaining informed consent from the donors and the hPDL tissues were used according to a protocol reviewed by the Ethics Committee of Nihon University School of Dentistry at Matsudo (EC 10-019).

\section{Stimulation of hPDL cells with wnt5a in the supernatant}

To examine the effects of wnt5a (R\&D Systems) on the mRNA expressions of ALP and OC, approximately $7 \times 10^{6}$ hPDL cells were transferred to $100 \mathrm{~mm}$ cell culture dishes. Confluent-stage cells were treated with wnt5a $(100 \mathrm{ng} / \mathrm{ml})$, which was added to the culture medium. For this experiment, we used the wnt5a concentration described previously $(21,22)$. To determine the time-course effects, the hPDL cells were treated with $100 \mathrm{ng} / \mathrm{ml}$ wnt5a in the supernatant for the indicated times $(0-24 \mathrm{~h})$. All of the above experiments were conducted in duplicate and in three different cell lines. After $24 \mathrm{~h}$ of incubation, total RNA was extracted for evaluation by a real-time polymerase chain reaction (PCR) (21). We used the cells treated without wnt5a as controls.

\section{Real-time polymerase chain reaction $(P C R)$}

Total RNA was extracted from the hPDL cells using an RNeasy Mini kit (Qiagen Co., Tokyo, Japan), and aliquots containing equal amounts of mRNA were subjected to realtime PCR. The mRNA was reverse transcribed to cDNA using the Prime Script RT Reagent Kit (Takara Co., Shiga,
Japan) according to the manufacturer's protocol. Real-time PCR amplification was performed using SYBR Premix Ex Taq (Takara Co.) in a thermal cycler (TP-800 Thermal Cycler Dice; Takara). The PCR primers for Jagged, and GAPDH were purchased from Takara Co. (Takara Co.) and designed with reference to the respective cDNA sequences (23), as follows:

ALP

Fw:5' -CTCGTTGACACCTGGAAGAGCTTCAAACCG-3'

Rv:5' -GGTCCGTCACGTTGTTCCTGTTCAGC-3'

COL1

Fw:5' -AGGGCTCCAACGAGATCGAGATCCG-3'

Rv:5' -TACAGGAAGCAGACAGGGCCAACGTCG-3'

GAPDH

Fw: 5' -GCACCGTCAAGGCTGAGAAC-3'

Rv: 5' -TGGTGAAGACGCCAGTGGA-3'

The data are expressed as the means \pm s. d. of six independent experiments.

\section{Statistical methods}

The values in each figure represent the mean \pm standard deviation (s.d.) for each group. The Mann-Whitney U-test was used to compare the means of groups with values of $\mathrm{P}<$ 0.05 and $\mathrm{P}<0.01$, which was considered to indicate a significant difference from the corresponding control.

\section{Results}

In vivo studies

Histological changes in periodontal tissues during tooth movement (HE staining)

For the control group $(0 \mathrm{~g})$ on day 7 after tooth movement, PDL specimens were composed of relatively dense connective tissue fibers and fibroblasts that regularly ran in a horizontal direction from the root cementum towards the alveolar bone. Blood capillaries were mainly recognized near the alveolar bone in the PDL. The alveolar bone and root surfaces were relatively smooth. In the experimental group $(10 \mathrm{~g})$ on day 7 after tooth movement, the arrangement of the fibers and fibroblasts became coarse and irregular (Fig. 2A, B)

\section{The protein expression levels of wnt5a}

Immunoreactivity for wnt5a was examined on day 7 after tooth movement. In the control group, wnt5a-positive cells were rarely observed in the PDL tissues (Fig. $2 \mathrm{C}$ ). In contrast, in the $\mathrm{TF}(10 \mathrm{~g})$ group, many wnt5a-positive cells 


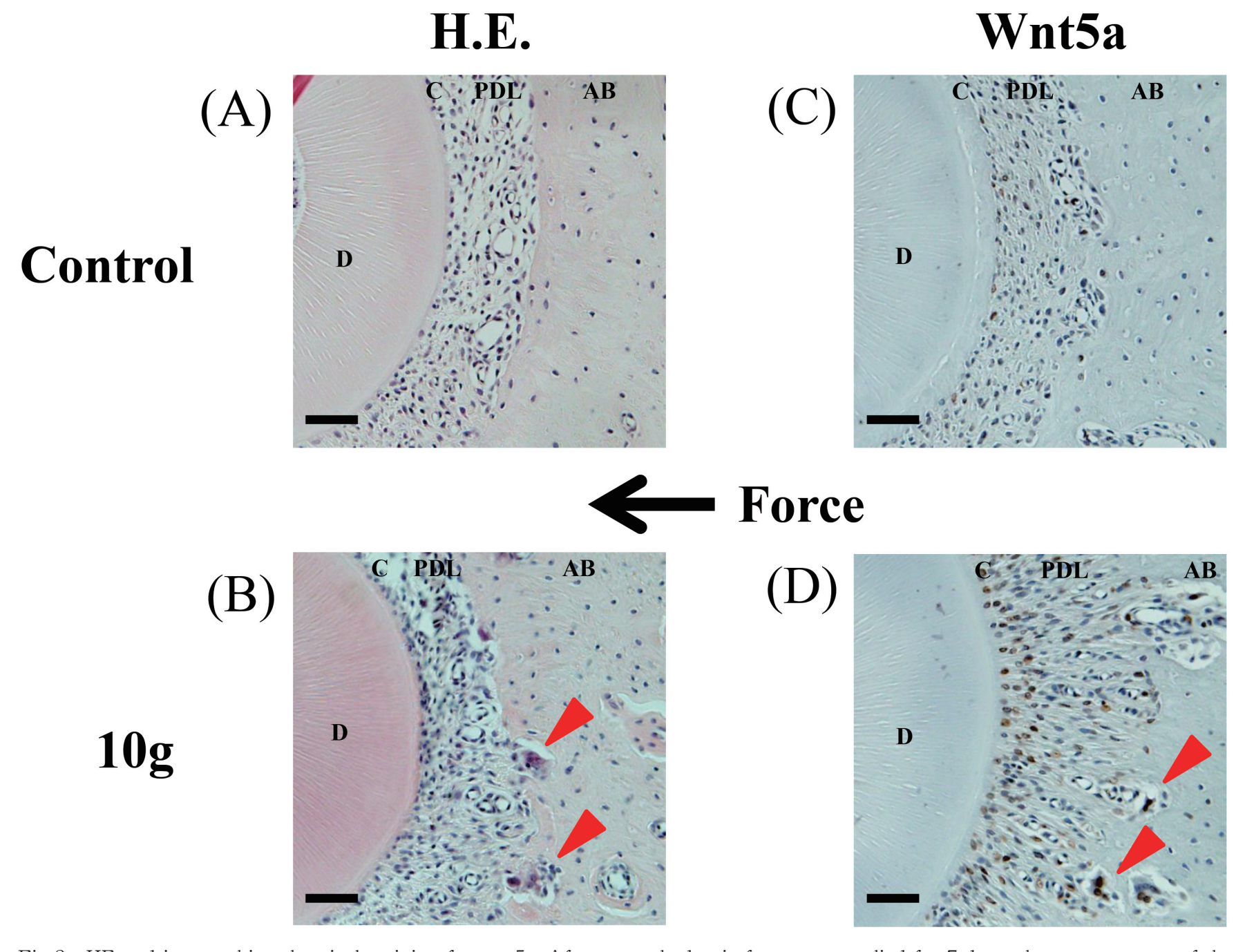

Fig.2 HE and immunohistochemical staining for wnt5a. After an orthodontic force was applied for 7 days, the arrangement of the fibers and fibroblasts was observed. It became coarse and irregular in the TF $(10 \mathrm{~g})$ group (arrow heads), but not in the control group (A, B). Immunoreactivity for wnt5a was observed on the alveolar bone surface and in the PDL tissues (arrow heads) in the TF (10 g) group (C, D). D: dentine, C: cementum, PDL: periodontal ligament, AB: alveolar bone. Original magnification $200 \times$, Scale bar: $50 \mu \mathrm{m}$

were observed in the PDL tissues (Fig. 2D). There was a greater level of increase in the number of wnt5a-positive cells in the TF group than in the control group (Fig. 3).

\section{In vitro studies}

The effects of wnt5a on the mRNA expressions of ALP and COL1 in the hPDL cells, as determined by a real-time PCR

To evaluate the effects of wnt5a on the mRNA levels of ALP and COL1, hPDL cells were stimulated with $100 \mathrm{ng} / \mathrm{ml}$ wnt5a for 0-24h. The mRNA expressions of ALP and COL1 were significantly increased comparison to the control cells, in a time-dependent manner until 24h (Figs. 4, 5). Significant increases in ALP and COL1 were detected at $6 \mathrm{~h}$ after the initiation of wnt5a stimulation, and the stimulatory effects of wnt5a were maintained for the whole stimulation period of $24 \mathrm{~h}$. These data indicate that wnt5a increases the expressions of ALP and COL1 by hPDL cells.

\section{Discussion}

When one considers the method of tooth movement, it can be stated that $10 \mathrm{~g}$ of light force application produced tooth movement without root resorption over a period of seven days in rats. Gonzales et al. (24) showed that, in comparison to when a heavier force was applied, $10 \mathrm{~g}$ of light force application produced significantly larger tooth movement with significantly less root resorption in rats over a period of 28 days. The optimum force for the movement of the rats' upper molars may be less than $10 \mathrm{~g}$ as previously sug- 


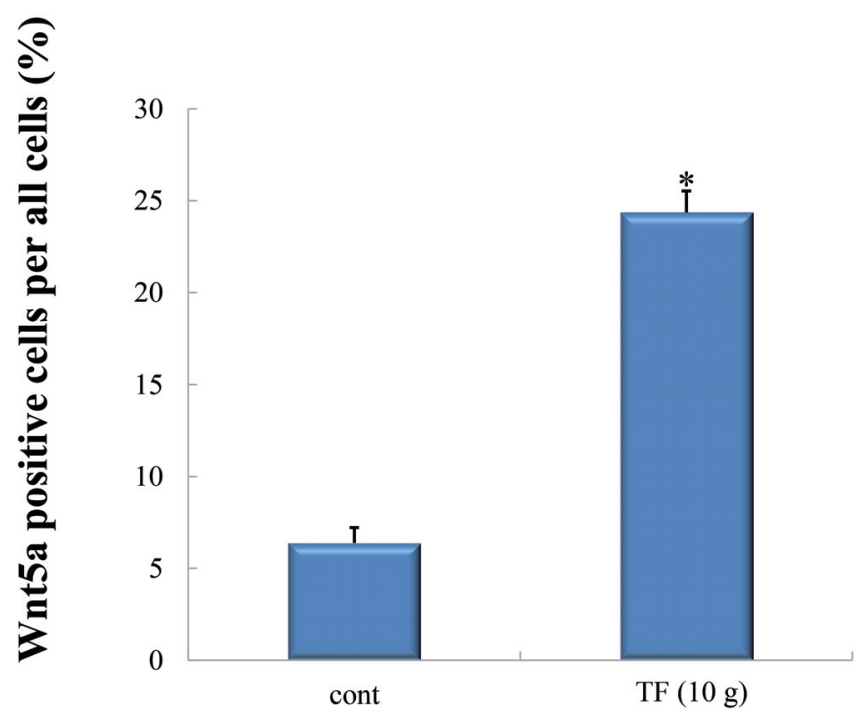

Fig.3 The number of Wnt5a-positive cells. The number of Wnt5a-positive cells was significantly different from the control $\left({ }^{*} \mathrm{p}<0.01\right)$.

gested(18). Therefore, the model in this study was supported as a method of efficient tooth movement.

In this study, in order to investigate whether the wnt signal is involved in the alveolar bone remodeling during orthodontic tooth movement (in an animal model), we moved the tooth by applying an optimum orthodontic force. On day 7 , the immunoreactivity for wnt5a was detected in the stretched PDL tissues subjected to the TF $(10 \mathrm{~g})$ group (Figs. 2C, D and 3). Kim et al.(25) reported that wnt signaling is regarded as a potent bone-stimulating signal. Baron et al.(26) reported that wht signaling is a key regulator of bone mass. Furthermore, Takada et al.(27) reported that mice with the deletion of a single allele of the wnt5a gene (wnt5a ${ }^{+/}$mice) exhibited a low bone mass phenotype with increased adipogenesis. Lim et al.(15) reported that the normally osteogenic nature of the PDL depends on wnt signaling. The expression of osteogenic markers is high in an environment where wnt signaling is upregulated(28). Taken together, the above findings indicate that wnt5a is involved in PDL metabolism and alveolar bone remodeling during orthodontic tooth movement.

In order to investigate the mechanisms responsible for the alterations in wnt5a induced by the orthodontic force during orthodontic tooth movement, the expression levels of ALP and COL1 mRNA were examined. The results indicated that the treatment of wnt5a significantly increased the mRNA expressions of ALP and COL1 from $6 \mathrm{~h}$ to $24 \mathrm{~h}$ in a time- dependent manner (Figs. 4, 5).

Considering the relationship between wnt signaling and mechanical stress, Robinson et al.(29) demonstrated that wnt/b-catenin signaling is required for mechanotransduction in bone. Premaraj et al.(30) reported that the wnt/bcatenin signaling pathway components are functional and activated by mechanical strain in hPDL cells. Shi et al.(31) reported that the uniaxial mechanical tension enhanced ALP and COL1 mRNA expressions of rat tendon-derived stem cells via the Wnt5a. These results suggest that the wnt5a response to orthodontic forces may induce the process of bone formation in hPDL cells. Interestingly, Fig2B shows that the number of PDL fibroblasts seemed to increase in response to TF. Fig. 4 shows that the expression of ALP did not increase until 9h (after which there was a subsequent increase). Furthermore, Vuga et al.(32) reported that wnt5a enhanced the proliferation of human lung fibroblast. Therefore, wnt5a may also enhance the proliferation of PDL cells and promote collagen synthesis. Further studies are necessary to investigate the relationships between the expression of COL1 and the proliferation of PDL cells subjected to orthodontic tooth movement .

In contrast, recent pathological and in vitro studies contradict the findings of the present study. The upregulation of RANK expression by wnt5a may be critical for osteoclastogenesis in response to RANKL secreted from osteoblast-lineage cells including osteocytes $(33,34)$. Maeda et al.(21) reported that wnt5a was highly expressed in synovial tissues from mice with type II collagen-induced arthritis. These findings suggest that wnt5a secreted from the synovial tissue is involved in bone destruction in rheumatoid arthritis (RA) $(21,35)$. The discrepancies between these previous and the present results may be due to differences in the cell types used and the stimuli applied to the cells.

In conclusion, we herein demonstrated that the wnt5a response to an orthodontic force may stimulate the process of bone formation from hPDL cells. Our results suggest that wnt5a, which is involved in wnt signaling, may play an important role in bone remodeling during orthodontic tooth movement.

\section{Acknowledgments}

This study was supported by Grants-in-Aid for Scientific Research from the Japan Society for the Promotion of Science (C:25463200, C: 26893289) and Nihon University 


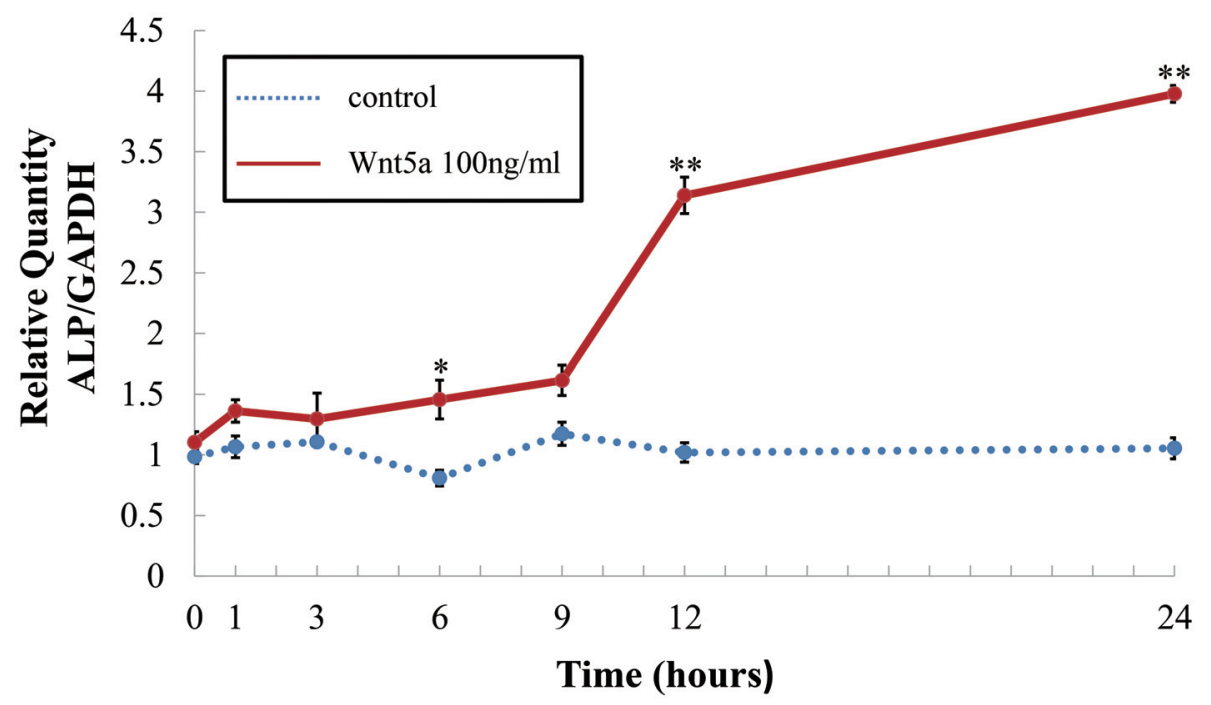

Fig.4 The time-course effect of wnt5a $(100 \mathrm{ng} / \mathrm{ml})$ on the mRNA expression of ALP in hPDL cells. The hPDL cells were treated with wnt5a, then the mRNA expression of ALP was observed to increase in a time-dependent manner for up to $24 \mathrm{~h}$ (Mann-Whitney U-test, $\left.{ }^{*} \mathrm{P}<0.05,{ }^{* *} \mathrm{P}<0.01\right)$. The data shown are representative of four independent experiments using samples from six different patients.

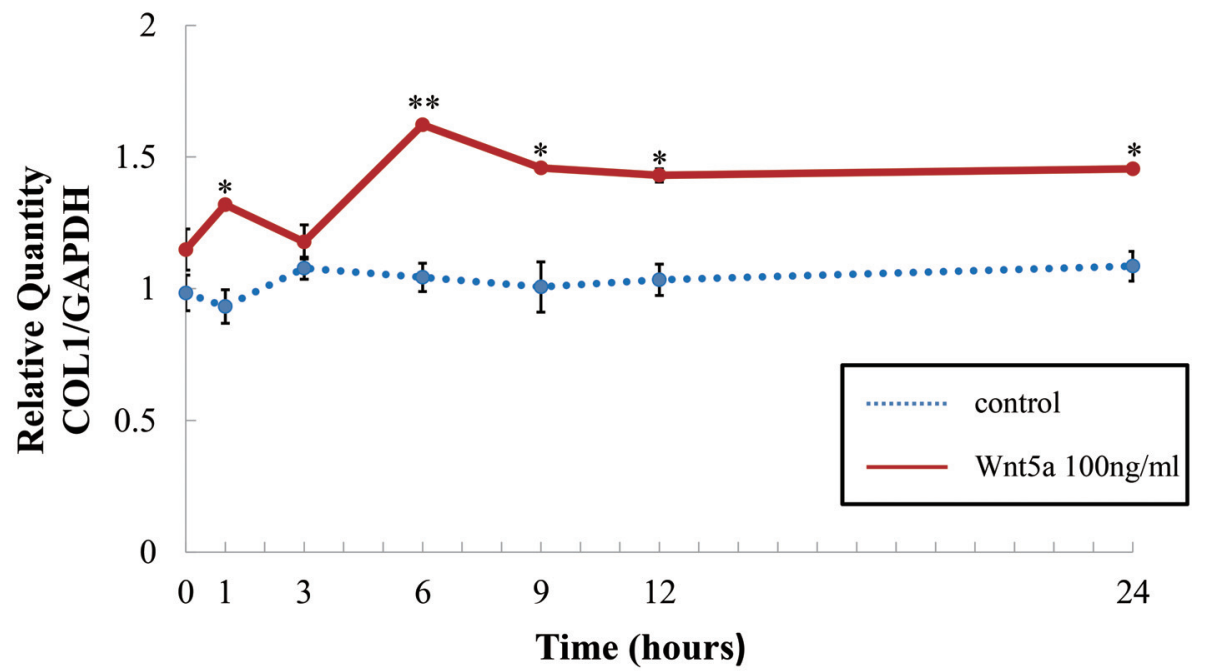

Fig.5 The time-course effect of wnt5a $(100 \mathrm{ng} / \mathrm{ml})$ on the mRNA expression of COL1 in hPDL cells. The hPDL cells were treated with wnt5a, then the mRNA expression of COL1 was observed to increase in a time-dependent manner for up to $24 \mathrm{~h}$ (Mann-Whitney U-test, $\left.{ }^{*} \mathrm{P}<0.05,{ }^{* *} \mathrm{P}<0.01\right)$. The data shown are representative of four independent experiments using samples from six different patients.

School of Dentistry at Matsudo established investigator grant for Kasai.

\section{References}

1 Frost HM: Skeletal structural adaptations to mechanical usage (SATMU): 1. Redefining Wolff's law: the bone modeling problem. Anat Rec, 226: 403-413, 1990.

2 Hattner R, Epker BN, Frost H: Suggested sequential mode of control of changes in cell behaviour in adult bone remodeling.
Nature, 206: 489-490, 1965.

3 Hadjidakis DJ, Androulakis II: Bone remodeling. Ann N Y Acad Sci, 1092: 385-396, 2006.

4 Pavlin D, Dove SB, Zadro R, Gluhak-Heinrich J: Mechanical loading stimulates differentiation of periodontal osteoblasts in a mouse osteoinduction model: Effect on type I collagen and alkaline phosphatase genes. Calcif Tissue Int, 67: 163-172, 2000.

5 Beertsen W, McCulloch CAG, Sodek J: The periodontal 
ligament: A unique, multifunctional connective tissue. Periodontol 2000, 13: 20-40, 1997.

6 Krishnan V, Davidovitch Z: Cellular, molecular, and tissuelevel reactions to orthodontic force. Am J Orthod Dentofacial Orthop, 129: 469 e1-32, 2006.

7 Gordon MD, Nusse R: Wnt signaling: multiple pathways, multiple receptors, and multiple transcription factors. J Biol Chem, 281: 22429-22433, 2006.

8 Westendorf JJ, Kahler RA, Schroeder TM: Wnt signaling in osteoblasts and bone diseases. Gene, 341: 19-39, 2004.

9 Barrow JR, Thomas KR, Boussadia-Zahui O, Moore R, Kemler R, Capecchi MR, McMahon AP: Ectodermal Wnt3/ $\beta$-catenin signaling is required for the establishment and maintenance of the apical ectodermal ridge. Genes Dev, 17: 394-409, 2003.

10 Hartmann C: Skeletal development--Wnts are in control. Mol Cells, 24: 177-184, 2007.

11 Westendorf JJ, Kahler RA, Schroeder TM: Wnt signaling in osteoblasts and bone diseases. Gene, 341: 19-39, 2004.

12 Krishnan V, Bryant HU, Macdougald OA: Regulation of bone mass by Wnt signaling. J Clin Investig, 116: 1202-1209, 2006.

13 Liu F, Kohlmeier S, Wang CY: Wnt signaling and skeletal development. Cell Signal, 20: 999-1009, 2008.

14 Lim WH, Liu B, Cheng D, Williams BO, Mah SJ, Helms JA: Wnt signaling regulates homeostasis of the periodontal ligament. J Periodontal Res, 49: 751-759, 2014.

15 Lim WH, Liu B, Mah SJ, Yin X, Helms JA: Alveolar bone turnover and periodontal ligament width are controlled by wnt. J Periodontol, 86: 319-326, 2015.

16 Rawadi G, Vayssière B, Dunn F, Baron R, Roman-Roman S: BMP-2 controls alkaline phosphatase expression and osteoblast mineralization by a Wnt autocrine loop. J Bone Miner Res, 18: 1842-1853, 2003.

17 Heo JS, Lee SY, Lee JC: Wnt/ $\beta$-catenin signaling enhances osteoblastogenic differentiation from human periodontal ligament fibroblasts. Mol Cells, 30: 449-454, 2010.

18 Kohno T, Matsumoto Y, Kanno Z, Warita H, Soma K: Experimental tooth movement under light orthodontic forces: rates of tooth movement and changes of the periodontium. J Orthod, 29: 129-135, 2002.

19 Asano M, Yamaguchi M, Nakajima R, Fujita S, Utsunomiya T, Yamamoto H, Kasai K: IL-8 and MCP-1 induced by excessive orthodontic force mediates odontoclastogenesis in periodontal tissues. Oral Dis, 17: 489-498, 2011.

20 Somerman MJ, Archer SY, Imm GR, Foster RA: A comparative study of human periodontal ligament cells and gingival fibroblasts in vitro. J Dent Res, 67: 66-70, 1988.

21 Maeda K, Kobayashi Y, Udagawa N, Uehara S, Ishihara A, Mizoguchi T, Kikuchi Y, Takada I, Kato S, Kani S, Nishita M, Marumo K, Martin TJ, Minami Y, Takahashi N: Wnt5a-Ror2 signaling between osteoblast-lineage cells and osteoclast precursors enhances osteoclastogenesis. Nat Med, 18:
405-412, 2012

22 Dai J, Hall CL, Escara-Wilke J, Mizokami A, Keller JM, Keller ET: Prostate cancer induces bone metastasis through Wntinduced bone morphogenetic protein-dependent and independent mechanisms. Cancer Res, 68: 5785-5794, 2008.

23 Zhao Y, Wang C, Li S, Song H, Wei F, Pan K, Zhu K, Yang P, $\mathrm{Tu}$ Q, Chen J.: Expression of Osterix in mechanical stressinduced osteogenic differentiation of periodontal ligament cells in vitro. Eur J Oral Sci. 116: 199-206, 2008.

24 Gonzales C, Hotokezaka H, Yoshimatsu M, Yozgatian JH, Darendeliler MA, Yoshida N: Force magnitude and duration effects on amount of tooth movement and root resorption in the rat molar. Angle Orthod, 78: 502-509, 2008.

25 Kim JB, Leucht P, Lam K, Luppen C, Ten Berge D, Nusse R, Helms JA: Bone regeneration is regulated by wnt signaling. J Bone Miner Res, 22: 1913-1923, 2007.

26 Baron R, Kneissel M: WNT signaling in bone homeostasis and disease: from human mutations to treatments. Nat Med, 19: 179-192, 2013

27 Takada I, Mihara M, Suzawa M, Ohtake F, Kobayashi S, Igarashi M, Youn MY, Takeyama K, Nakamura T, Mezaki Y, Takezawa S, Yogiashi Y, Kitagawa H, Yamada G, Takada S, Minami Y, Shibuya H, Matsumoto K, Kato S: A histone lysine methyltransferase activated by non-canonical Wnt signalling suppresses PPAR-gamma transactivation. Nat Cell Biol, 9: 1273-1285, 2007.

28 Zhong Z1, Zylstra-Diegel CR, Schumacher CA, Baker JJ, Carpenter AC, Rao S, Yao W, Guan M, Helms JA, Lane NE, Lang RA, Williams BO: Wntless functions in mature osteoblasts to regulate bone mass. Proc Natl Acad Sci U S A, 109: E2197-2204, 2012.

29 Robinson JA, Chatterjee-Kishore M, Yaworsky PJ, Cullen DM, Zhao W, Li C, Kharode Y, Sauter L, Babij P, Brown EL, Hill AA, Akhter MP, Johnson ML, Recker RR, Komm BS, Bex FJ: Wnt/beta-catenin signaling is a normal physiological response to mechanical loading in bone. J Biol Chem, 281: 31720-31728, 2006.

30 Premaraj S1, Souza I, Premaraj T: Mechanical loading activates $\beta$-catenin signaling in periodontal ligament cells. Angle Orthod, 81: 592-599, 2011.

31 Shi Y, Fu Y, Tong W, Geng Y, Lui PP, Tang T, Zhang X, Dai K: Uniaxial mechanical tension promoted osteogenic differentiation of rat tendon-derived stem cells (rTDSCs) via the Wnt5aRhoA pathway. J Cell Biochem, 113: 3133-3142, 2012.

32 Vuga LJ, Ben-Yehudah A, Kovkarova-Naumovski E, Oriss T, Gibson KF, Feghali-Bostwick C, Kaminski N: WNT5A is a regulator of fibroblast proliferation and resistance to apoptosis. Am J Respir Cell Mol Biol. 41: 583-589, 2009.

33 Nakashima T, Hayashi M, Fukunaga T, Kurata K, Oh-Hora M, Feng JQ, Bonewald LF, Kodama T, Wutz A, Wagner EF, Penninger JM, Takayanagi H: Evidence for osteocyte 
regulation of bone homeostasis through RANKL expression. Nat Med, 17: 1231-1234, 2011.

34 Xiong J1, Onal M, Jilka RL, Weinstein RS, Manolagas SC, O'Brien CA: Matrix-embedded cells control osteoclast forma- tion. Nat Med, 17: 1235-1241, 2011.

35 Maeda K, Takahashi N, Kobayashi Y: Roles of Wnt signals in bone resorption during physiological and pathological states. J Mol Med (Berl), 91: 15-23, 2013. 